\title{
Serotonin Transporter and Seasonal Variation in Blood Serotonin in Families with Obsessive-Compulsive Disorder
}

\author{
Gregory L. Hanna, M.D., Joseph A. Himle, Ph.D., George C. Curtis, M.D.,
} Diane Q. Koram, M.S.W., Jeremy Veenstra-Vander Weele, A.B., Bennett L. Leventhal, M.D., and Edwin H. Cook, Jr., M.D.

The serotonin transporter (HTT) is a candidate gene for obsessive-compulsive disorder (OCD) that has been associated with anxiety-related traits. The long (1) and short (s) variants of the HTT promoter have different transcriptional efficiencies. HTT promoter genotype and blood 5-HT concentration were examined in 70 subjects from 20 families ascertained through children and adolescents with a DSM-III-R diagnosis of OCD. The HTT promoter variant had a significant effect on blood 5-HT content. Subjects with the $1 / 1$ and $1 / \mathrm{s}$ genotypes had significantly higher blood 5-HT levels than did those with the $\mathrm{s} / \mathrm{s}$ genotype. There was a significant interaction between HTT promoter genotype and seasonal variation in blood 5-HT content, with significant seasonal differences in 5-HT occurring only in the subjects with the $1 / 1$ genotype. Further studies of the regulation of HTT gene expression are indicated. [Neuropsychopharmacology 18:102-111, 1998] (C) 1998 American College of Neuropsychopharmacology. Published by Elsevier Science Inc.
KEY WORDS: Serotonin transporter; Gene regulation; Serotonin; Blood platelet; Seasonal variation; Obsessivecompulsive disorder; Family study

The serotonin transporter $(H T T=S L C 6 A 4)$ is a plausible candidate gene for obsessive-compulsive disorder (OCD) and several other psychiatric disorders (Altemus et al. 1996; Lesch et al. 1995; Ogilvie et al. 1996). It has been associated with anxiety-related traits in two predominantly male samples (Lesch et al. 1996). The human serotonin transporter protein (5-HTT) is encoded by a

From the Department of Psychiatry (GLH, JAH, GCC, DQK), University of Michigan, Ann Arbor, Michigan; and the Departments of Psychiatry and Pediatrics (JVVW, BLL, EHC), University of Chicago, Chicago, Illinois.

Address correspondence to: Gregory L. Hanna, M.D., Department of Psychiatry, Child and Adolescent Psychiatric Hospital, University of Michigan, 1500 East Medical Center Drive, Ann Arbor, MI 48109-0390.

Received January 28, 1997; revised April 16, 1997; accepted June 9, 1997. single gene on chromosome 17q12 (Gelernter et al. 1995; Ramamoorthy et al. 1993). A complementary deoxyribose nucleic acid (cDNA) encoding the 5-HTT in the human midbrain raphe complex has been isolated, and its identity with the human platelet serotonin (5-HT) transporter site has been demonstrated (Lesch et al. 1993a,b).

HTT gene transcription is regulated by a deletion/ insertion polymorphism in the promoter (Heils et al. 1995). The long (l) and short (s) variants of this polymorphic region have different transcriptional efficiencies in transfection assays and lymphoblastoid cell lines (Heils et al. 1996; Lesch et al. 1996). The short allele reduces the transcriptional efficiency of the HTT gene promoter, resulting in decreased 5-HTT binding and 5-HT uptake in lymphoblasts (Lesch et al. 1996). Studies of HTT gene expression in lymphoblast cell lines from 10 subjects with different genotypes suggested that the polymorphism has more of a dominant-recessive than a codominant-additive effect, with the short variant ap- 
pearing dominant to the long variant. However, the dominant mode of action of the short allele has been questioned (Goldman 1996).

Because of the small sample size in that study and the importance of the HTT, we examined the relationship between the HTT promoter variant and whole blood 5-HT concentration in 70 individuals from 20 families ascertained through children and adolescents between 10 and 17 years of age with a DSM-III-R diagnosis of OCD. Sampling through early-onset cases can be a useful strategy in identifying a more clearly genetic or homogeneous form of a disorder (Lander and Schork 1994). Family studies have demonstrated that OCD is often familial and that the morbid risk of the disorder is higher among the relatives of early-onset probands than among the relatives of late-onset probands (Bellodi et al. 1992; Pauls et al. 1995).

The selective response of OCD to potent 5-HT transporter inhibitors (serotonin reuptake inhibitors, SRIs) has suggested that a serotonergic abnormality may be involved in OCD (Goodman et al. 1990; Leonard et al. 1989). The 5-HTT is an initial site of action for those drugs and is crucial to the termination of serotonergic neurotransmission (Amara and Kuhar 1993). Two treatment studies of childhood OCD using clomipramine, a potent $5-\mathrm{HT}$ transporter inhibitor, have demonstrated a significant correlation between clinical improvement and a marked reduction in either platelet 5-HT or whole blood 5-HT content, reflecting the effect of the drug on the platelet uptake site (Flament et al. 1987; Hanna et al. 1993). Pharmacologic challenge studies have provided additional evidence of a serotonergic dysfunction in OCD (Barr et al. 1992; Murphy et al. 1989).

Blood platelets have been investigated as a peripheral model of the storage, release, and active uptake of 5-HT by serotonergic neurons (Owens and Nemeroff 1994). Results from a twin study have indicated that the number of 5-HT uptake sites may be under genetic control in blood platelets (Meltzer and Arora 1988). Similarly, results from selective breeding experiments with rats have demonstrated that platelet 5-HT content has a marked heritable component (Jernej and Cicin-Sain 1990). Studies characterizing the platelet 5-HTT with paroxetine, a selective 5-HT transporter inhibitor, have found reduced binding capacity in OCD (Marazziti et al. 1996; Sallee et al. 1996). Some data have also suggested that the normal seasonal variation in platelet 5-HT content is disrupted in OCD (Brewerton et al. 1993).

More than $99 \%$ of blood 5-HT is contained in thrombocytes (Kremer et al. 1990). Platelet 5-HT has been measured in either whole-blood or platelet-rich plasma. However, measurements made in platelet-rich plasma are complicated by platelet heterogeneity and by difficulties in determining platelet yield. Thus, a wholeblood assay is preferred for measuring platelet 5-HT (Anderson et al. 1987).

Because of the evidence cited above, it was hypothesized that the HTT promoter variant would be associated with whole blood 5-HT content, with the $l / l$ genotype having higher whole blood 5-HT levels than the $s / s$ genotype. Possible interactions influencing blood 5-HT content between HTT promoter genotype and seasonal variation or psychiatric diagnosis were also examined. The study provides preliminary evidence that the long allele has an overall dominant effect on blood 5-HT levels, whereas the short allele provides more stability in those levels across the seasons.

\section{METHODS}

\section{Subjects}

Blood samples were obtained for whole blood 5-HT assay and genotyping from 70 subjects living in lower Michigan who were members of the first 20 families enrolled in an ongoing family study of OCD. They ranged in age from 10 to 89 years and consisted of six OCD probands, 55 first-degree relatives, six second-degree relatives, and three third-degree relatives. One subject was African-American; all other subjects were Caucasian. Demographic, clinical, and biochemical characteristics of the subjects are summarized in Table 1. Blood

Table 1. Demographic, Clinical, and Biochemical Characteristics of 20 Families with Obsessive-Compulsive Disorder

\begin{tabular}{|c|c|c|c|c|}
\hline & Probands $(n=6)$ & Parents $(n=34)$ & Siblings $(n=21)$ & Other Relatives ( $n=9$ ) \\
\hline $\operatorname{Sex}(M / F)$ & $5 / 1$ & $18 / 16$ & $13 / 8$ & $6 / 3$ \\
\hline Current age (yrs) & $\begin{array}{l}15.3 \pm 1.2 \\
(13 \text { to } 17)\end{array}$ & $\begin{array}{l}45.2 \pm 5.3 \\
\text { ( } 35 \text { to } 55)\end{array}$ & $\begin{array}{l}19.4 \pm 5.3 \\
(10 \text { to } 31)\end{array}$ & $\begin{array}{l}57.5 \pm 18.3 \\
(39 \text { to } 89)\end{array}$ \\
\hline Lifetime OCD $n(\%)$ & $6(100)$ & $6(18)$ & $5(24)$ & $3(33)$ \\
\hline Onset of OCD (yrs) & $\begin{array}{l}9.4 \pm 2.6 \\
(5 \text { to } 16)\end{array}$ & $\begin{array}{c}16.1 \pm 5.3 \\
(6 \text { to } 31)\end{array}$ & $\begin{array}{l}12.8 \pm 2.7 \\
(10 \text { to } 16)\end{array}$ & $\begin{array}{l}9.0 \pm 5.3 \\
(5 \text { to } 15)\end{array}$ \\
\hline Blood serotonin (nmol/L) & $\begin{array}{c}932 \pm 250 \\
(590 \text { to } 1197)\end{array}$ & $\begin{array}{c}964 \pm 350 \\
(329 \text { to } 1946)\end{array}$ & $\begin{array}{c}954 \pm 377 \\
(363 \text { to } 1822)\end{array}$ & $\begin{array}{c}979 \pm 387 \\
(556 \text { to } 1737)\end{array}$ \\
\hline Blood serotonin $(\mathrm{ng} / \mathrm{ml})$ & $\begin{array}{c}164 \pm 44 \\
(104 \text { to } 211)\end{array}$ & $\begin{array}{c}170 \pm 62 \\
(58 \text { to } 343)\end{array}$ & $\begin{array}{c}168 \pm 66 \\
(64 \text { to } 321)\end{array}$ & $\begin{array}{c}172 \pm 68 \\
(98 \text { to } 306)\end{array}$ \\
\hline
\end{tabular}


5-HT was not assayed for 28 other family members because they had received antiobsessional, antidepressant, or other psychotropic medications during the 2 months before assessment (23), had a medical illness or medical treatment that could potentially influence blood 5 -HT content (3), or refused venipuncture (2). The group that had recently received antiobsessional/antidepressant medication that can lower platelet 5-HT content consisted of 14 probands, five first-degree relatives, and four second-degree relatives.

Children and adolescents between 10 and 17 years of age with a current diagnosis of OCD served as probands. They were recruited from clinics at the University of Michigan Medical Center and from the local chapters of the Obsessive-Compulsive Foundation and the Tourette's Syndrome Association. Informed consent was obtained from both parents and informed assent was obtained from each proband. After ascertainment of potential probands, interviews were conducted to determine whether the individuals met DSM-III-R criteria for OCD (American Psychiatric Association 1987). All probands were interviewed directly. The exclusion criteria for the OCD probands were (1) chronic neurological disorder (other than tic disorder), (2) full-scale IQ $\leqslant 70$, (3) DSMIII-R diagnosis of autistic disorder, schizophrenia, or bipolar disorder, (4) current psychosis or suicidal behavior, (5) currently living away from both biological parents, and (6) adoption. After a diagnosis of OCD had been established for the proband, permission to contact other relatives was requested.

\section{Family Study Procedures}

Direct Interviews. After informed consent and assent were obtained, all probands and siblings between 10 and 17 years were interviewed with the Schedule for Affective Disorders and Schizophrenia for School Age Children-Epidemiological Version (KIDDIE-SADS-E) (Orvaschel 1987). The interview was completed independently with a parent of the subject as well as with the subject. The interview was supplemented with the sections on OCD and the tic disorders from the Schedule for Tourette and Other Behavioral Syndromes (Version C1) (Pauls and Hurst 1991a). All first-degree relatives 18 years and older were interviewed with the Structured Clinical Interview for DSM-III-R (Spitzer et al. 1990, 1992; Williams et al. 1992) and the sections on OCD and the tic disorders from the Schedule for Tourette and Other Behavioral Disorders (Version A1) (Pauls and Hurst 1991b).

Both interviews included a version of the Yale-Brown Obsessive Compulsive Scale (Y-BOCS: Goodman et al. 1989a,b) modified to obtain information about the lifetime occurrence of obsessive and compulsive symptoms. A series of screening questions designed to cover all criteria for a DSM-III-R diagnosis of OCD preceded the Y-BOCS checklist (Pauls et al. 1991a,b, 1995). All other parts of the interview were identical to either the KIDDIE-SADS-E (child) or the SCID (adult). The same interviews were used in the diagnostic assessment of second- and third-degree relatives.

Family History Interviews. Additional information on all first-degree and second-degree relatives 18 years and older was obtained with the Family Informant Schedule and Criteria (FISC) (Mannuzza et al. 1985). The mothers of the probands were interviewed with the FISC regarding her spouse, adult offspring, parents, and siblings. The fathers of the probands were interviewed with the FISC regarding his spouse, parents, and siblings. Thus, two types of data were obtained about all adult subjects: (1) information from direct structured interviews and (2) personal history information from a biological relative and/or spouse.

All interviews were audiotaped as well as coded on paper. Subjects who had received psychiatric or neurological services were asked to sign a written release of information form so that copies of their clinical records could be requested and added to the structured interview data.

Interviewers. All interviewers had at least a master's degree and clinical training in child or adult psychopathology. They were trained to at least $90 \%$ diagnostic agreement with the individual instruments. The interviewers were confined to interviewing either probands and siblings between 10 and 18 years of age or adult relatives. The interviewer for a given proband was not involved with any of the interviews with other members of the family. Interviewers did not know whether each person they interviewed was a proband with OCD, a relative of a proband with OCD, a comparison subject, or a relative of a comparison subject.

\section{Best-Estimate Diagnoses}

After completion of all interviews for an individual, all available materials (personal interview data, family history data, and clinical records) were collated. All information identifying or describing the proband was removed so that diagnostic ratings could be completed by raters blind to proband diagnosis. The blind diagnosticians were never given a complete family to evaluate at one time, and all diagnostic evaluations of probands were done separately from those of the relatives.

Best-estimate diagnoses were made independently by two investigators using DSM-III-R criteria. If a subject had sufficient symptoms to meet all criteria, a "definite" diagnosis was assigned. A "subthreshold" diagnosis was made if a subject definitely had a history of obsessions and/or compulsions, but lacked compelling evidence for the following criterion: (1) marked distress, (2) duration of obsessive-compulsive symptoms 
for more than $1 \mathrm{~h}$ a day, or (3) significant interference in the person's normal routine, occupational (or academic) functioning, or usual social activities or relationships with others. When major disagreements occurred between two diagnosticians, consensus diagnoses were reached with the assistance of a third diagnostician, following established procedures developed for the diagnosis of other psychiatric disorders (Leckman et al. 1982).

\section{Biochemical and Molecular Genetic Methods}

Blood was drawn from the subjects into vacutainer tubes containing ethylenediaminetetraacetic acid and mixed by gentle inversion. The samples were immediately transported to the laboratory and stored frozen at $-70^{\circ} \mathrm{C}$ until the time of batch assay. All samples were drawn and prepared by the same phlebotomist (G.L.H.). Diet and time of blood sampling were not controlled. Whole-blood 5-HT was analyzed by high pressure liquid chromatography (HPLC) with fluorometric detection (Anderson et al. 1981). 5-hydroxytryptophan was used as an internal standard. Intraassay and interassay coefficients of variation were $0.8 \%$ and $3.6 \%$, respectively. There was no difference in interassay variance when samples that had been frozen for several days between assays were compared with samples that had been frozen for up to 24 months between assays (Cook 1990). Assays were performed blind to all demographic and diagnostic information.

Blood 5-HT levels decline with age to stable adult levels by age 12, and the slope of that decline from ages 10 to 12 is shallow (Ritvo et al. 1971). Blood 5-HT levels are generally stable in an individual over several months (Yuwiler et al. 1970) and are not affected by ordinary changes in diet (Anderson et al. 1984; Badcock et al. 1987). An early study found that after acute loading with tryptophan, the precursor of 5-HT, changes in blood 5-HT levels were transient with a return to baseline levels within $8 \mathrm{~h}$ (Yuwiler et al. 1981). A more recent study found no detectable changes in blood 5-HT levels after either oral or intravenous administration of tryptophan (Cook et al. 1992). Prior work has detected no significant diurnal variation in blood $5-\mathrm{HT}$ content in adults (Kremer et al. 1990). Gender effects are small with females having approximately $10 \%$ higher whole blood 5-HT levels than males (Cook et al. 1988). AfricanAmerican subjects have been reported to have higher whole-blood 5-HT levels in preliminary studies (Cuccaro et al. 1993; Cook et al. 1995).

Seasonal variations have been reported for some parameters related to 5-HT metabolism and function in humans, including both platelet 5-HT uptake (Arora et al. 1984; Codd et al. 1988; Egrise et al. 1986; Marazziti et al. 1990), content (Brewerton et al. 1993; Jakovljevic et al. 1997; Wirz-Justice and Pühringer 1978; Mann et al. 1992), plasma 1-tryptophan (Maes et al. 1995), and ${ }^{3} \mathrm{H}$-imi- pramine binding (Egrise et al. 1986; DeMet et al. 1991). However, the results on circannual changes in platelet 5-HT content have been inconsistent (Brewerton et al. 1993; Jakovljevic et al. 1997; Wirz-Justice and Pühringer 1978; Mann et al. 1992). To examine the effect of season on blood 5-HT content, seasons were defined by their respective solstices and equinoxes (i.e., winter, December 21 through March 20; spring, March 21 through June 20; summer, June 21 through September 20; and fall, September 21 through December 20) (D'Hondt et al. 1996; Maes et al. 1995). Because of the limited number of subjects in some cells, the year was also divided in half according to the equinoxes for further analysis. The study extended from September 17, 1994 to November 23, 1996.

Oligonucleotide primers flanking the HTT polymorphic region and corresponding to the nucleotide positions ranging from $-1,416$ to $-1,397$ (stpr5: 5'-GGCGTTGCCGCTCTGAATTGC) and from -910 to -889 (stpr3: 5'-GAGGGACTGAGCTGGACAACCCAC) of the HTT gene regulatory region were used to generate a 484/528-bp fragment (Heils et al. 1995, 1996). A second primer set corresponding to nucleotide positions ranging from -1403 to -1384 (HTTp2A, 5'-TGAATGCCAGCACCTAACCC-3') and from -973 to -954 (HTTp2B, 5' -TTCTGGTGCCACCTAGACGC- $3^{\prime}$ ) successfully amplified a 406/450-bp fragment from DNAs that failed to amplify with the first set. The second primer set was used to confirm 41 samples originally genotyped with the 484/ 528 -bp fragment. PCR was performed in a $10-\mu l$ volume containing approximately $50 \mathrm{ng}$ of genomic template, 1 $\mu \mathrm{mol} / \mathrm{L}$ of each primer, $200 \mu \mathrm{mol} / \mathrm{L}$ each dATP, dCTP, and dTTP, $100 \mu \mathrm{m}$ each of dGTP, and $7^{\prime}$-deaza-dGTP, 0.6 units of Taq polymerase (AmpliTaq; Perkin Elmer), $1.5 \mathrm{mmol} / \mathrm{L} \mathrm{MgCl}_{2}, 5 \%$ DMSO, $10 \mathrm{mmol} / \mathrm{L}$ Tris- $\mathrm{HCl}, 50$ $\mathrm{mmol} / \mathrm{L} \mathrm{KCl}$, and $0.001 \%$ gelatin. Samples were processed in a Perkin Elmer GeneAmp PCR System 9600, through 40 cycles of $30 \mathrm{~s}$ at $95^{\circ} \mathrm{C}, 30 \mathrm{~s}$ at $61^{\circ} \mathrm{C}$, and $1 \mathrm{~min}$ at $72^{\circ} \mathrm{C}$, followed by $10 \mathrm{~min}$ at $72^{\circ} \mathrm{C}$. Eight microliters of PCR product were mixed with three microliters of Sigma loading buffer. Ten microliters of that mixture were separated at room temperature on $4 \%$ agarose (Perkin Elmer) gels containing $0.5 \mu \mathrm{g} / \mathrm{mL}$ ethidium bromide in TAE buffer $(40 \mathrm{mmol} / \mathrm{L}$ Tris-Acetate, 1 $\mathrm{mmol} / \mathrm{L}$ EDTA, $\mathrm{pH}$ 8.0). Each gel contained one lane of a 100-bp ladder (Gibco BRL) (see Figure 1). Representative homozygote bands were cut from the gel, eluted, and cycle sequenced and found to have the sequences previously reported for the long and short variants of HTT (Heils et al. 1996) (see Figure 2).

\section{Data Analysis}

The effects of gender, family membership, psychiatric diagnosis, blood collection season, and HTT promotor genotype on blood 5-HT concentration were examined 
with analysis of variance (ANOVA). Post hoc comparisons were made with Fisher's Protected LSD test. Pearson correlation coefficients were calculated to analyze the relationship between continuous variables. Data are reported as mean \pm standard deviation. All probability values reported are two-tailed. Significance is stipulated as $p \leqslant .05$, with trends of $.05<p<.10$ indicated.

\section{RESULTS}

There was no significant relationship between blood 5 -HT concentration and either gender or age. There was no evidence for a familial effect on blood 5-HT content
( $p>.10)$. Of the 70 subjects, 19 had a definite diagnosis of OCD and one a subthreshold diagnosis of OCD. Only one proband and one relative had a history of chronic tics. Blood 5-HT content had no relationship with a current or lifetime diagnosis of OCD or with diagnostic subtypes of OCD (primary versus secondary, tic-related versus non-tic-related, or familial versus sporadic OCD) (all $p$ values $>.10$ ). Twenty individuals had a lifetime diagnosis of major depression; however, major depression had no relationship with blood 5-HT content.

PCR-based genotype analysis of the 70 subjects with blood 5-HT levels revealed allele frequencies of $53 \%$ for the long $(l)$ and $47 \%$ for the short (s) allele. HTT pro-

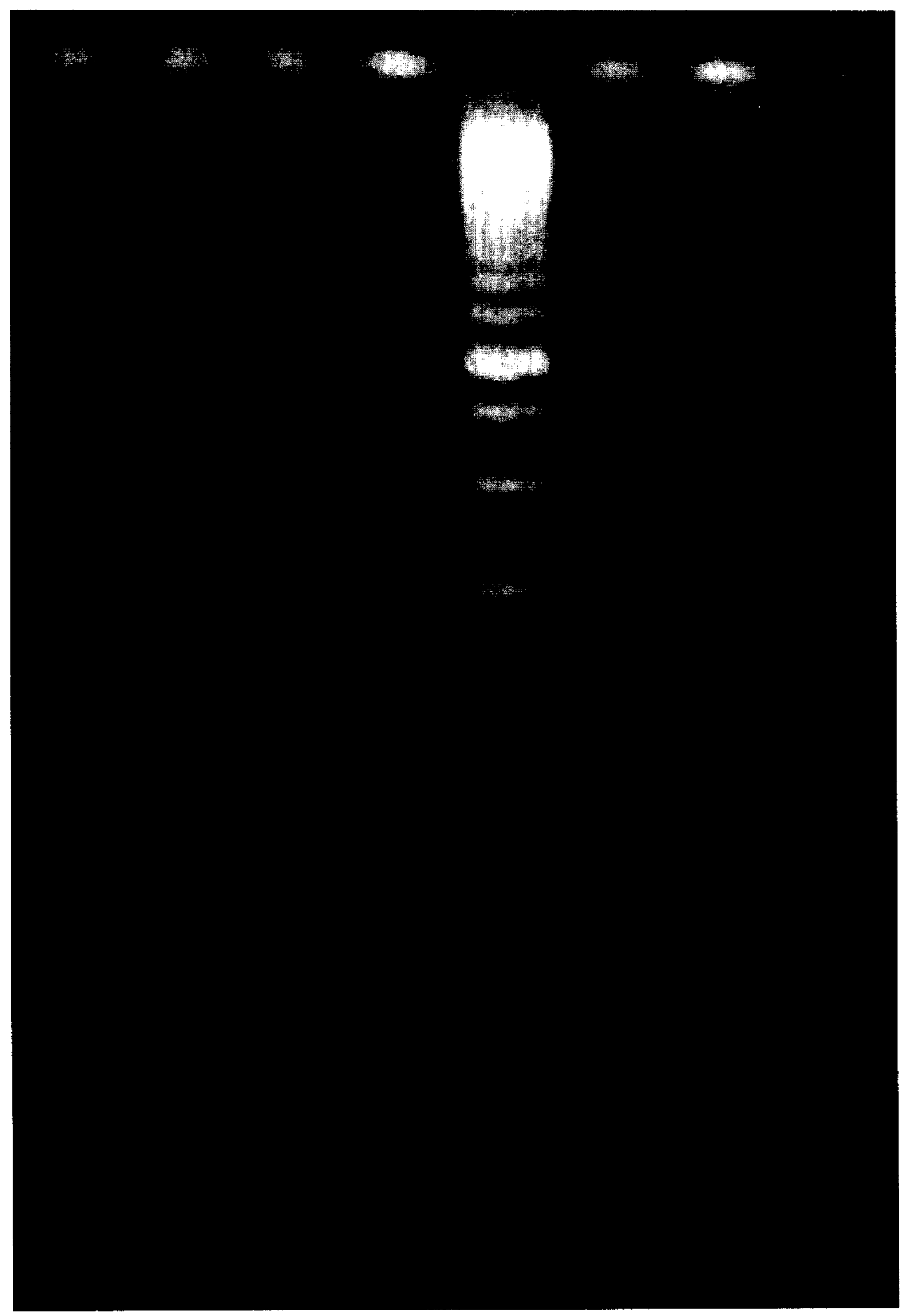

Figure 1. Representative agarose gel used to distinguish the long and short variants of the serotonin transporter promoter variant. A $100-b p$ ladder is included for approximate sizing in lane 5. Lanes 1, 3, 4, 6, and 8 are heterozygotes at HTT. Lane 2 is a homozygous long variant, and lane 7 is a homozygous short variant of HTT. 
moter genotypes were consistent with Hardy-Weinberg equilibrium: $20(29 \%) l /, 34(48 \%) l / s$, and $16(23 \%) \mathrm{s} / \mathrm{s}$. There were no significant differences between the individuals with the three genotypes in age, gender, or season of blood sampling.

With a two-factor ANOVA, the HTT promoter variant had a significant effect on blood 5-HT content $(\mathrm{F}=$ 3.47, $d f=2,58, p<.04$ ). Blood 5-HT levels associated with the $l / l$ and $l / s$ genotypes were significantly higher than those associated with the $s / s$ genotype $(1047 \pm 400$ versus $772 \pm 311 \mathrm{nmol} / \mathrm{L}, p<.02$ and $997 \pm 309$ versus $772 \pm 311, p<.04$, respectively). There was a trend for a seasonal effect on blood 5-HT content $(\mathrm{F}=2.45, d f=$ $3,58, p<.08)$. Furthermore, there was a significant interaction between HTT promoter genotype and seasonal variation in blood 5-HT content $(\mathrm{F}=2.9, d f=6,58, p<$ .02 ). When the subjects with the $l / l$ genotype were analyzed separately from the others, the seasonal variation in blood 5-HT content was significant $(\mathrm{F}=4.73, d f=3,26$, $p<.02$ ). In contrast, the other two genotypes had relatively stable blood 5-HT levels throughout the year.

When the year was divided in half by the equinoxes, the interaction between the HTT promotor variant and the equinox divisions in blood 5-HT content was significant $(\mathrm{F}=4.04, d f=2,64, p<.03)$. The subjects with the $l / l$ genotype had significantly higher blood 5 -HT levels from March 21 through September 20 than from September 21 through March $20(1267 \pm 464$ versus $820 \pm 128$ $\mathrm{nmol} / \mathrm{L}, t=2.88, d f=18, p<.01$ ), whereas the other two genotypes had no significant differences between the equinox divisions in blood 5-HT levels (see Figure 3).

\section{DISCUSSION}

The results indicate the HTT promoter variant has a weak, but significant effect on blood 5-HT content accounting for about $8 \%$ of the variance in $5-\mathrm{HT}$ levels. The effect of HTT promoter genotype on blood 5-HT content is mediated through the platelet 5-HT transporter; however, the measurement of blood 5-HT is not equivalent to assessing the platelet 5-HT transporter itself. Factors other than the 5-HT transporter also affect blood 5-HT levels, including 5-HT synthesis by trypotophan hydroxylase in the intestinal wall, platelet 5-HT release, and clearance by the lung, liver, kidney, and capillary bed (Anderson et al. 1987).

The results also suggest that the long allele of the HTT promoter variant is associated with higher blood 5-HT levels than is the short allele, and that the long allele is dominant to the short allele in its effect on blood $5-\mathrm{HT}$ content. The effect of the long allele on blood 5-HT

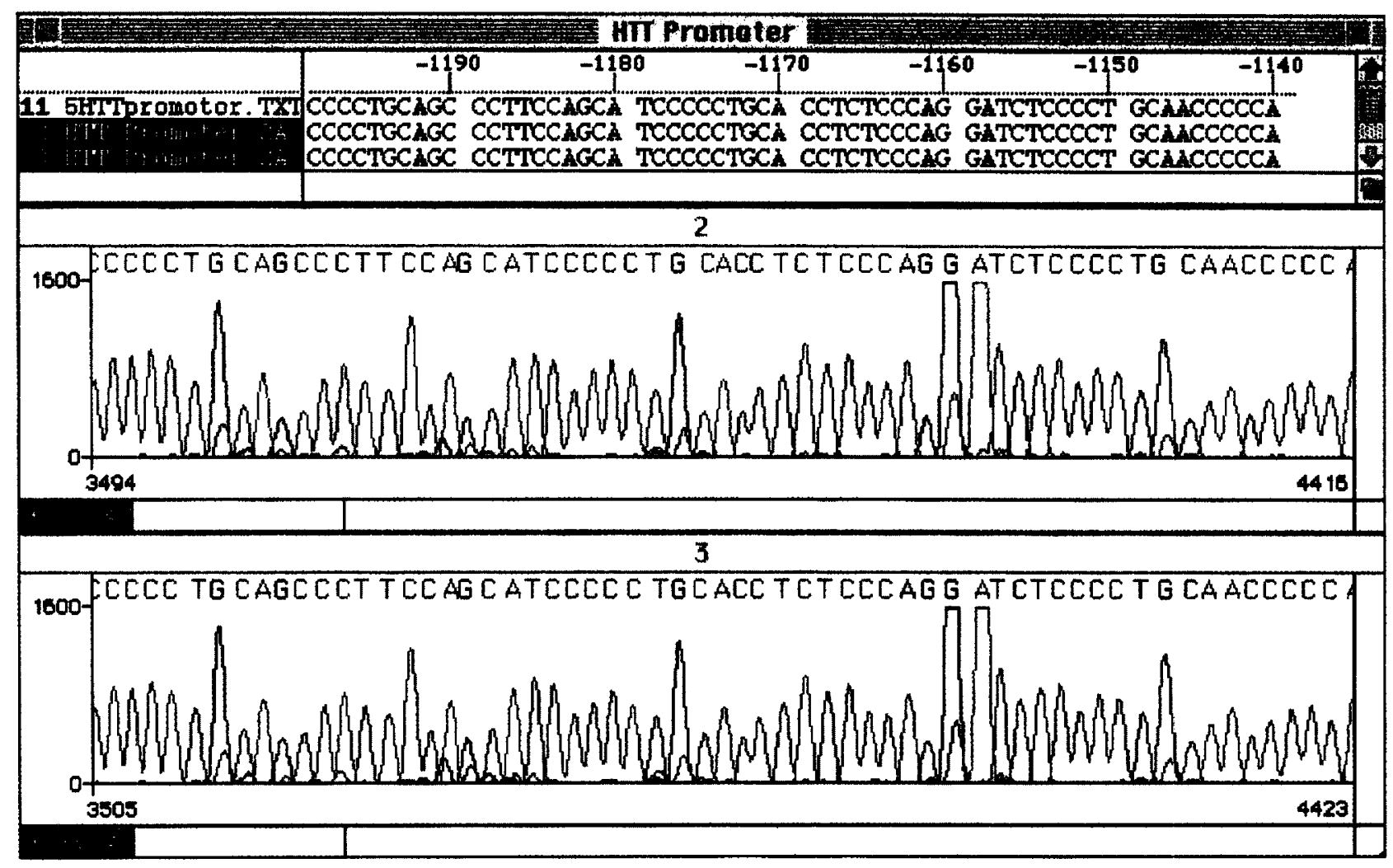

Figure 2. Sequencing electorpherogram showing confirmation of the identity of the serotonin transporter promoter variants cut out from gel in Figure 1. 
content is consistent with the association observed between the long allele and increased 5-HTT binding and 5-HT uptake in lymphoblast cell lines (Lesch et al. 1996). However, the dominance of the long allele in this study of blood 5-HT content is contrary to the observations on HTT expression in the lymphoblast studies of 10 subjects (Lesch et al. 1996). This may be due to differences in tissue-specific transcriptional regulation of HTT in megakaryocytes relative to lymphoblasts. Studies of HTT promoter genotype, HTT mRNA expression, and 5-HT transporter function in the CNS are needed to define the relationship of the HTT promoter variant to central serotonergic activity.

The interaction between the HTT promoter variant and seasonal variation in blood 5-HT content is consistent with the extensive literature on seasonal rhythms in serotonergic measures (Brewerton et al. 1993; Cappiello et al. 1996; D'Hondt et al. 1996; Maes et al. 1995). Subjects with the $l / l$ genotype had substantial seasonal differences in blood 5-HT levels. In contrast, subjects with a short variant $(l / s$ or $s / s)$ had minimal fluctuation in blood 5-HT levels. Thus, subjects with the $l / s$ genotype had relatively high, but stable 5 -HT levels. It has

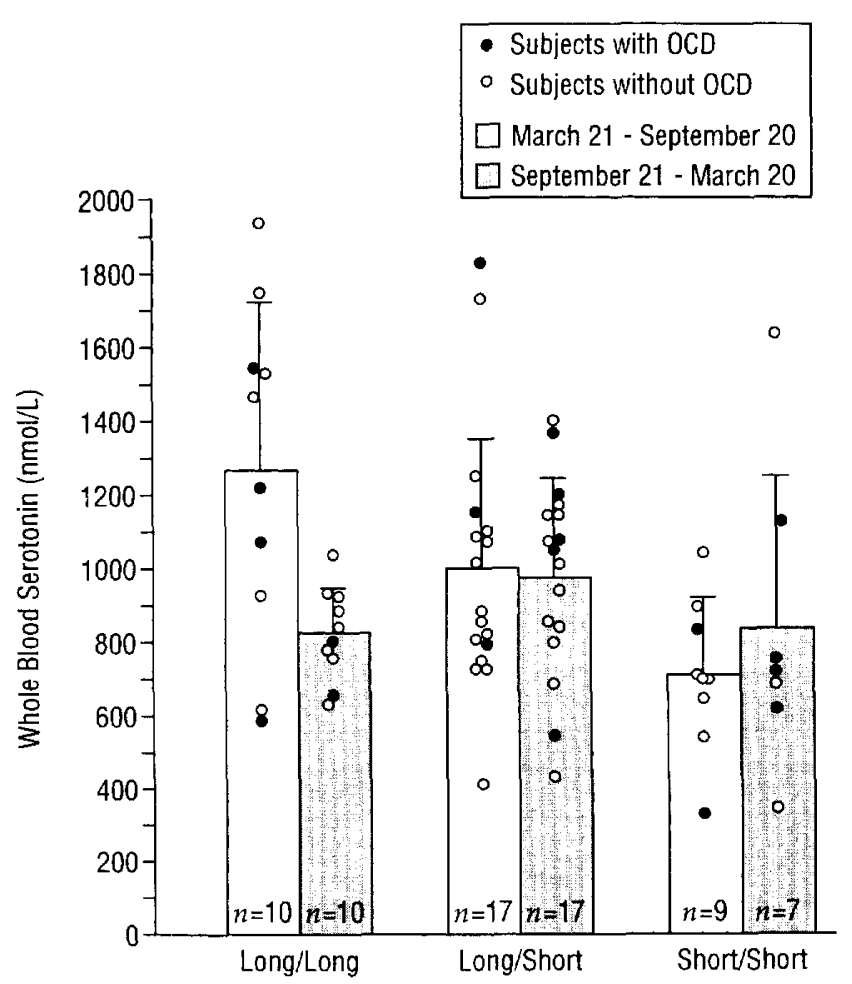

Figure 3. Serotonin transporter promoter genotype and whole blood serotonin (5-HT) concentration in unmedicated subjects. Extensions of bars indicate SD; OCD, obsessivecompulsive disorder. Subjects homozygous for the long variant had significantly higher blood 5-HT levels from March 21 through September 20 than from September 21 through March $20(p<.01)$. been estimated that genetic effects account for at least $29 \%$ of the variance in the seasonal rhythms in mood and behavior (Madden et al. 1996). Further studies are necessary to confirm the seasonal modulation of HTT gene expression and to determine whether the HTT promoter variant has a role in the seasonality of mood disorders and violent suicide (Maes et al. 1995).

There was no evidence for the familiality of blood 5-HT content in our study. It is difficult to reconcile this negative finding with studies that have found positive correlations in either platelet or whole blood 5-HT concentration between children with either autism or disruptive behavior disorders and their first-degree relatives (Abramson et al. 1989; Cook et al. 1990, 1995; Kuperman et al. 1985). The present study may have failed to detect a correlation because $70 \%$ of the probands and $13 \%$ of the parents were taking antiobsessional/antidepressant medication that resulted in their exclusion from the analysis. The sample was also inadequate for determining the effects of puberty and ethnicity on blood 5-HT content.

$O C D$ and various diagnostic subtypes of $O C D$ had no apparent effect on 5-HT content. This is consistent with a previous report of no difference between OCD subjects and normal controls in blood 5-HT levels (Hanna et al. 1991). The number of sporadic OCD cases was too small to determine whether familial OCD differed from sporadic OCD in blood 5-HT content, as was reported in the earlier study (Hanna et al. 1991). An insufficient number of normal controls and their family members were available for analysis. Repeated measures of blood 5-HT levels in OCD subjects and unrelated normal controls will be necessary to determine whether the normal circannual rhythm in blood 5-HT content is disrupted in OCD.

In summary, the study provides preliminary evidence that the long allele of the HTT promoter variant has an overall dominant effect on blood 5-HT levels, whereas the short allele may provide more stability in those levels across the seasons. Besides the limitations noted above, other limitations of our study deserve comment. Multiple statistical tests were performed without adjustment of the alpha level. Along with blood 5-HT content, it would have been informative to have assessed the relationship between the HTT promoter variant and binding to the platelet 5-HTT. Data on climatic variables, such as minutes of sunlight, ambient temperature, relative humidity, and air pressure, would have allowed a components analysis of the seasonal effect on blood 5-HT levels (D'Hondt et al. 1996; Maes et al. 1995). A large sample of unrelated individuals would have allowed the use of multivariate techniques such as cosinar or spectral analyses that may have provided a more sensitive assessment of seasonal changes than the techniques used in this study (Cappiello et al. 1996). Further studies are needed to determine whether 
the HTT promoter variant is a quantitative trait locus for serontonergic measures and to assess the clinical significance of these findings.

\section{ACKNOWLEDGMENTS}

This work was supported by NIH Grant MH-01065, the Obsessive Compulsive Foundation, and the Brain Research Foundation, University of Chicago. The authors thank Elizabeth Weidmer-Mikhail, M.D., Kristin Rohrbach, M.S.W., Katherine Gold, M.S.W., Hedieh Haghighatgou, M.S.W., and Kevin Hartzell for their assistance.

\section{REFERENCES}

Abramson RK, Wright HH, Carpenter R, Brennan W, Lumpuy O, Cole E, Young SR (1989): Elevated blood serotonin in autistic probands and their first-degree relatives. J Autism Develop Disord 19:397-407

Altemus M, Murphy DL, Greenberg B, Lesch KP (1996): Intact coding region of the serotonin transporter gene in obsessive-compulsive disorder. Am J Med Genet 67: $409-411$

Amara S, Kuhar M (1993): Neurotransmitter transporters: Recent progress. Annu Rev Neurosci 16:73-93

American Psychiatric Association (1987): Diagnostic and Statistical Manual of Mental Disorders, 3rd ed, revised. Washington, DC, American Psychiatric Association

Anderson GM, Young JG, Cohen DJ, Schlicht KR (1981): Liquid chromatographic determination of serotonin and tryptophan in whole blood and plasma. Clin Chem 27:775-776

Anderson GM, Teff KL, Young SN (1984): Effect of a meal on human whole blood serotonin. Gastroenterology 88:86-89

Anderson GM, Feibel FC, Cohen DJ (1987): Determination of serotonin in whole blood, platelet-rich plasma, plateletpoor plasma and plasma ultrafiltrate. Life Sci 40:10631070

Arora RC, Kregel L, Meltzer HY (1984): Seasonal variations of serotonin uptake in normal controls and depressed patients. Biol Psychiatry 19:795-804

Badcock NR, Spence JG, Stern LM (1987): Blood serotonin levels in adults, autistic and nonautistic children - with a comparison of different methodologies. Ann Clin Biochem 24:625-634

Barr LC, Goodman WK, Price LH, McDougle CJ, Charney DS (1992): The serotonin hypothesis of obsessive compulsive disorder: Implications of pharmacologic challenge studies. J Clin Psychiatry 53:17-28

Bellodi L, Sciuto G, Diaferia G, Ronchi P, Smeraldi E (1992): Psychiatric disorders in the families of patients with obsessive-compulsive disorder. Psychiatry Res 42:111-120

Brewerton TD, Flament MR, Rapoport JL, Murphy DL (1993): Seasonal effects on platelet 5-HT content in patients with OCD and controls. Arch Gen Psychiatry 50:409

Cappiello A, Malison RT, McDougle CJ, Vegso SJ, Charney DS, Heninger GR, Price LH (1996): Seasonal variation in neuroendocrine and mood responses to IV 1-tryptophan in depressed patients and healthy subjects. Neuropsychopharmacology 15:475-483

Codd EE, McAlister TW, Walker RF (1988): Factors affecting serotonin uptake into human platelets. Psychopharmacology 95:180-184

Cook EH (1990): Autism: Review of neurochemical investigation. Synapse 6:292-308

Cook EH, Anderson GM, Heninger G, Fletcher KE, Freedman DX, Leventhal BL (1992): Tryptophan loading in hyperserotonemic and normoserotonemic adults. Biol Psychiatry 31:525-528

Cook EH, Leventhal BL, Freedman DX (1988): Serotonin and measured intelligence. J Autism Develop Disord 18:553559

Cook EH, Leventhal BL, Heller W, Metz J, Wainwright M, Freedman DX (1990): Autistic children and their firstdegree relatives: Relationships between serotonin and norepinephrine levels and intelligence. J Neuropsychiatry Clin Neurosci 2:268-274

Cook EH, Stein MA, Ellison T, Unis AS, Leventhal BL (1995): Attention deficit hyperactivity disorder and whole blood serotonin levels: Effects of comorbidity. Psychiatry Res $57: 13-20$

Cuccaro ML, Wright HH, Abramson RK, Marsteller FA, Valentine J (1993): Whole-blood serotonin and cognitive functioning in autistic individuals and their first-degree relatives. J Neuropsychiatry Clin Neurosci 5:94-101

DeMet E, Reist C, Bell KM, Gerner RH, Chicz-DeMet A, Warren S, Wu J (1991): Decreased seasonal mesor of platelet ${ }^{3} \mathrm{H}$-imipramine binding in depression. Biol Psychiatry 29:427-440

D'Hondt P, Maes M, Leysen JE, Gommeren W, Heylen L, DeMeyer F, Scharpe S, Peeters D, Desnyder R (1996): Seasonal variation in platelet $\left[{ }^{3} \mathrm{H}\right]$ paroxetine binding in healthy volunteers. Neuropsychopharmacology 15:187198

Egrise D, Rubinstein M, Schouten A, Cantraine F, Mendlewicz J (1986): Seasonal variations of platelet serotonin uptake and ${ }^{3} \mathrm{H}$-imipramine binding in normal and depressed subjects. Biol Psychiatry 21:283-292

Flament MF, Rapoport JL, Murphy DL, Berg CJ, Lake CR (1987): Biochemical changes during clomipramine treatment of childhood obsessive-compulsive disorder. Arch Gen Psychiatry 44:219-225

Gelernter J, Pakstis AJ, Kidd KK (1995): Linkage mapping of serotonin transporter protein gene SLC6A4 on chromosome 17. Hum Genet 95:677-680

Goldman D (1996): High anxiety. Science 274:1483

Goodman WK, Price LH, Rasmussen SA, Mazure C, Fleischmann RL, Hill CL, Heninger GR, Charney DS (1989a): The Yale-Brown Obsessive-Compulsive Scale I. Development, use, and reliability. Arch Gen Psychiatry 46: 1006-1011

Goodman WK, Price LH, Rasmussen SA, Mazure C, Delgado P, Heninger GR, Charney DS (1989b): The Yale-Brown Obsessive-Compulsive Scale II. Validity. Arch Gen Psychiatry 46:1012-1016

Goodman WK, Price LH, Delgado PL, Palumbo J, Krystal JH, Nagy LM, Rasmussen SA, Heninger GR, Charney DS 
(1990): Specificity of serotonin reuptake inhibitors in the treatment of obsessive-compulsive disorder. Comparison of fluvoxamine and desipramine. Arch Gen Psychiatry 47:577-585

Hanna GL, Yuwiler A, Cantwell DP (1991): Whole blood serotonin in juvenile obsessive-compulsive disorder. Biol Psychiatry 29:738-742

Hanna GL, Yuwiler A, Cantwell DP (1993): Whole blood serotonin during clomipramine treatment of juvenile obsessive-compulsive disorder. J Child Adolesc Psychopharmacol 3:223-229

Heils A, Teufel A, Petri S, Seemann M, Bengel D, Balling U, Riederer P, Lesch KP (1995): Functional promoter and polyadenylation site mapping of the human serotonin (5-HT) transporter gene. J Neural Transm 102:247-254

Heils A, Teufel A, Petri S, Stöber G, Riederer P, Bengel D, Lesch KP (1996): Allelic variation of human serotonin transporter gene expression. J Neurochemistry 66:2621-2624

Jakovljevic M, Mück-Seler D, Pivac N, Ljubicic D, Bujas M, Dodig G (1997): Seasonal influence on platelet 5-HT levels in patients with recurrent major depression and schizophrenia. Biol Psychiatry 41:1028-1034

Jernej B, Cicin-Sain L (1990): Platelet serotonin level in rats is under genetic control. Psychiatry Res 32:167-174

Kremer HPH, Goekoop JG, Van Kempen GMJ (1990): Clinical use of the determination of serotonin in whole blood. J Clin Psychopharmacol 10:83-87

Kuperman S, Beeghly JHL, Burns TL, Tsai LY (1985): Serotonin relationships of autistic probands and their firstdegree relatives. Journal of the American Academy of Child Psychiatry 24:186-190

Lander ES, Schork NJ (1994): Genetic dissection of complex traits. Science 265:2037-2048

Leckman JF, Sholomskas D, Thompson WE, Belanger A, Weissman MM (1982): Best estimate of lifetime psychiatric diagnoses: A methodological study. Arch Gen Psychiatry 39:879-883

Leonard HL, Swedo SE, Rapoport JL, Coffey M, Cheslow D (1989): Treatment of obsessive-compulsive disorder with clomipramine and desipramine in children and adolescents: A double-blind crossover comparison. Arch Gen Psychiatry 46:1088-1092

Lesch KP, Wolozin BL, Estler HC, Murphy DL, Riederer P (1993a): Isolation of a cDNA encoding the human brain serotonin transporter. J Neural Transm 91:67-73

Lesch KP, Wolozin BL, Murphy DL, Riederer P (1993b): Primary structure of the human platelet serotonin (5-HT) uptake site: Identity with the brain 5-HT transporter. J Neurochem 60:2319-2322

Lesch KP, Gross J, Franzek E, Wolozin BL, Riederer P, Murphy DL (1995): Primary structure of the serotonin transporter in unipolar depression and bipolar depression. Biol Psychiatry 37:215-223

Lesch KP, Bengel D, Heils A, Sabol SZ, Greenberg BD, Petri S, Benjamin J, Muller CR, Hamer DH, Murphy DL (1996): Association of anxiety-related traits with a polymorphism in the serotonin transporter gene regulatory region. Science 274:1527-1531

Madden PAF, Heath AC, Rosenthal NE, Martin NG (1996):
Seasonal changes in mood and behavior: The role of genetic factors. Arch Gen Psychiatry 53:47-55

Maes M, Scharpé S, Verkerk R, D'Hondt P, Peeters D, Cosyns P, Thompson P, De Meyer F, Wauters A, Neels H (1995): Seasonal variation in plasma l-tryptophan availability in healthy volunteers. Arch Gen Psychiatry 52:937-946

Mann JJ, McBride PA, Anderson GM, Mieczkowski TA (1992): Platelet and whole blood serotonin content in depressed inpatients: Correlations with acute and lifetime psychopathology. Biol Psychiatry 32:243-257

Mannuzza S, Fyer AJ, Endicott J, Klein DF (1985): Family Information Schedule and Criteria (FISC). New York, Anxiety Disorders Clinic, New York Psychiatric Institute

Marazziti D, Falcone MF, Castrogiovaninni P, Cassano GB (1990): Seasonal serotonin uptake changes in healthy subjects. Mol Chem Neuropathol 13:145-153

Marazziti D, Rossi A, Gemignani A, Giannaccini G, Pfanner C, Milanfranchi A, Presta S, Lucacchini A, Cassano GB (1996): Decreased platelet ${ }^{3} \mathrm{H}$-paroxetine binding in obsessive-compulsive disorder. Neuropsychobiology 34 : 184-187

Meltzer H, Arora R (1988): Genetic control of serotonin uptake in blood platelets: A twin study. Psychiatry Res 24:263-269

Murphy DL, Zohar J, Benkelfat C, Pato MT, Pigott TA, Insel TR (1989): Obsessive-compulsive disorder as a 5-HT subsystem-related behavioral disorder. Br J Psychiatry 155:15-24

Ogilvie A, Battersby S, Bubb VJ, Fink G, Harmar AJ, Goodwin GM, Smith CAD (1996): Polymorphism in the serotonin transporter gene associated with major depression. Lancet 347:731-733

Orvaschel H (1987): Schedule for Affective Disorders and Schizophrenia for School Aged Children-Epidemiologic Version (K-SADS-E), 4th ed. Philadelphia, PA, Medical College of Pennsylvania

Owens MH, Nemeroff CB (1994): Role of serotonin in the pathophysiology of depression: Focus on the serotonin transporter. Clin Chem 40:288-295

Pauls DL, Alsobrook JP, Goodman W, Rasmussen S, Leckman JF (1995): A family study of obsessive-compulsive disorder. Am J Psychiatry 152:76-84

Pauls DL, Hurst CR (1991a): Schedule for Tourette and Other Behavioral Disorders (Adult Form, Version A1). New Haven, CT, Child Study Center, Yale University School of Medicine

Pauls DL, Hurst CR (1991b): Schedule for Tourette and Other Behavioral Syndromes (Adult on Child Form, Version C1). New Haven, CT, Child Study Center, Yale University School of Medicine

Ramamoorthy S, Bauman A, Moore K, Han H, Yang-Feng T, Chang A, Ganapathy V, Blakely R (1993): Antidepressant- and cocaine-sensitive human serotonin transporter: molecular cloning, expression, and chromosomal localization. Proc Natl Acad Sci USA 90:2542-2546

Ritvo ER, Yuwiler A, Geller E, Plotkin S, Mason A, Saegar K (1971): Maturational changes in blood serotonin levels and platelet counts. Biochem Med 5:90-96

Sallee FR, Richman H, Beach K, Sethuraman G, Nesbitt L (1996): Platelet serotonin transporter in children and 
adolescents with obsessive-compulsive disorder or Tourette's syndrome. J Am Acad Child Adolesc Psychiatry 35:1647-1656

Spitzer RL, Williams JBW, Gibbon M, First MB (1990): Structured Clinical Interview for DSM-III-R. Washington, DC, American Psychiatric Press

Spitzer RL, Williams JBW, Gibbon M, First MB (1992): The structured clinical interview for DSM-III-R (SCID): I. History, rationale, and description. Arch Gen Psychiatry 49:624-629

Williams JBW, Gibbon M, First MB, Spitzer RL, Davies M, Borus J, Howes MJ, Kane J, Pope HG, Rounsaville B Wittchen H-U (1992): The structured clinical interview for DSM-III-R (SCID): II. Multisite test-retest reliability. Arch Gen Psychiatry 49:630-636

Wirz-Justice A, Pühringer W (1978): Seasonal incidence of an altered diurnal rhythm of platelet serotonin in unipolar depression. J Neural Transm 42:45-53

Yuwiler A, Brammer GL, Morley JE, Raleigh MJ, Flannery JW, Geller E. (1981): Short-term and repetitive administration of oral tryptophan in normal men. Arch Gen Psychiatry 38:619-626

Yuwiler A, Plotkin S, Geller E, Ritvo ER (1970): A rapid accurate procedure for the determination of serotonin in whole human blood. Biochem Med 3:426-436 